\title{
Faktor-Faktor Yang Mempengaruhi Customer Retention Di PT. Erafone Mega Mall Manado
}

\author{
Trecya. S. M. Lompoliuw \\ Riane Johnly. Pio \\ Roy F. Runtuwene \\ Program Studi Administrasi Bisnis, Jurusan Ilmu Administrasi \\ Fakultas Ilmu Sosial dan Ilmu Politik Universitas Sam Ratulangi Manado \\ trecyaichalompoliuw@gmail.com
}

\begin{abstract}
The objective of this research was to Analyzing the variables of trust, commitment of communication and handling The complaint simultaneously and partially towards to customer retention of mobile products and most dominant variables of trust, commitment, communication and handling The complaint in influencing customer retention at PT Erafone Mega Mall. Where companies must be able to have strategies in attracting and retaining customers such as relationship marketing strategies that have 4 variables, namely : trust, commitment, communication and secure of complaints. When a company is able to carry out that strategy well, consumers will feel satisfied and comfortable with the sold products and services provided by the company to consumers and when it goes well, it is likely that consumers will buy again and can recommend products from the company. - This type of research is a type of descriptive research verification. The data collection technique in this study used questionnaire and literature. To examine the effect of customer retention on customer satisfaction by using multiple linear regression test analysis techniques. The tools used in the test instrument data are validity and reliability test, assumption test (normality test, multicellularity test and heteroscedasticity test). The results of this study indicate that the four independent variables have a significant and simultaneous effect on customer retention. While the most dominant influence on customer retention is customer trust in using PT ERAFONE Manado products.
\end{abstract}

\section{Keywords: Customer Retention, Relationship Marketing}

\section{Pendahuluan}

Sumber daya manusia merupakan aspek terpenting dalam sebuah perusahaan. Disamping sumber daya alam dan sumber daya modal, sumber daya manusia juga memiliki peran yang sangat penting guna mencapai tujuan dan keberhasilan perusahaan. Keberhasilan suatu perusahaan dipengaruhi oleh kinerja karyawan. Dalam kondisi persaingan yang ketat di dunia bisnis seperti sekarang ini. setiap perusahaan harus mampu meningkatkan kapabilitas untuk bersaing dengan perusahaan lain sehingga bisa bertahan hidup dan terus berkembang.

Dari hasil pengamatan awal menunjukkan bahwa pelanggan PT. Erafone di dalam mengelola relationship marketing belum secara optimal memberikan kontribusi terhadap retensi pelanggan (customer retention) dalam artian mempertahankan pelanggannya 
untuk membeli kembali produk perusahaan tersebut. Perusahaan-perusahaan yang ingin unggul harus memiliki strategi-strategi dalam memenangkan persaingan, termasuk strategi dalam menarik pelanggan, mempertahankan pelanggan, dan mengelola pelanggan. Perusahaan dituntut untuk mampu memahami pelanggan lebih dekat agar terjalin ikatan yang saling menguntungkan diantara kedua belah pihak. Salah satu strategi yang dapat menunjang keberhasilan bisnis adalah dengan menerapkan relationship marketing.

Relationship marketing menyediakan suatu pendekatan yang membantu perusahaan dalam menciptakan hubungan dengan pelanggan dan pihak lain yang saling terkait dalam proses bisnis (Kotler dan Amstrong, 2014:34).

Relationship marketing dipengaruhi oleh empat variabel, yaitu kepercayaan, komitmen, komunikasi, dan penanganan keluhan. Menjalin hubungan yang baik dengan pelanggan, memberikan kemudahan serta kenyamanan dimana hal tersebut bisa terus terjalin dan menciptakan hubungan emosional yang lebih dalam antara perusahaan dengan pelanggan, kemudian dapat membentuk suatu kesetiaan pelanggan terhadap perusahaan yang disebut customer retention (Ndubisi, 2009). customer retention adalah proses yang membuat pelanggan setia terhadap perusahaan tertentu dan melakukan pembelian ulang atau menggunakan jasa kembali dari perusahaan tersebut. Mempertahankan pelanggan jauh lebih menguntungkan bagi perusahaan dari pada mencari pelanggan baru (Danish dan Humayon,2015:29).

Menurut Lapalelo, dkk (2015) kualitas pelayanan dapat diketahui dengan cara membandingkan persepsi para konsumen atas pelayanan yang nyata diterima atau diperoleh dengan pelayanan yang sesungguhnya diharapkan dan diinginkan terhadap atribut pelayanan suatu perusahaan.

Berdasarkan latar belakang di atas maka tujuan yang akan dicapai dalam penelitian ini ialah untuk mengetahui pengaruh variabel kepercayaan, komitmen, komunikasi, dan penanganan keluhan secara simultan dan parsial terhadap customer retention produk handphone pada PT. Erafone Mega Mall Manado. Serta menganalisis variabel kepercayaan, komitmen, komunikasi, dan penanganan keluhan yang paling dominan dalam mempengaruhi customer retention pada produk handphone pada PT. Erafone Mega Mall Manado. 


\section{Metode Penelitian}

Jenis penelitian ini di lihat dari tingkat eksplanasi merupakan jenis penelitian deskriptif verifikatif. Penelitian ini dilakukan di PT. Erafone Mega Mall Manado bertempat dan telah dilaksanakan pada bulan Februari 2019.

Dalam melakukan penelitian ini, peneliti menempuh beberapa langkah diantaranya diadakan terlebih dahulu studi terhadap masalah yang akan diangkat dari beberapa literatur dan informasi dari internet yang ada. Selanjutnya diadakan persiapan untuk pencarian data yang diperlukan untuk dapat menganalisis masalah melalui kuesioner (Data Primer).

\section{Sampel yang digunakan dalam} penelitian ini ialah sebanyak 105 responden.Teknik pengumpulan data yang digunakan dalam penelitian ini, menggunakan metode kuesioner dan kepustakaan. Untuk meneliti pengaruh dari relationship marketing (komitmen, kepercayaan, komuniksi, dan penanganan keluhan dengan menggunakan uji regresi linear berganda.

\section{Hasil Dan Pembahasan}

Berikut ini adalah perhitungan hasil analisis regresi linear berganda dari variabel-variabel yang diteliti, variabel independen yang terdiri dari: variabel Kepercayaan (X1),variabel Komitmen
(X2), variabel Komunikasi (X3);dan Variabel Penanganan Masalah (X4) serta variabel Customer Retention (Y) untuk variabel dependen.

Tabel 1 : Hasil Analisis Regresi Berganda

\begin{tabular}{lcc}
\hline \multicolumn{1}{c}{ Variabel } & B & Std Error \\
\hline (Constant) & 1,554 & 3,657 \\
Kepercayaan (X1) & 0,166 & 0,077 \\
Komitmen (X2) & 0,268 & 0,098 \\
Komunikasi (X3) & 0,247 & 0,095 \\
$\begin{array}{l}\text { Penanganan Masalah } \\
\text { (X4) }\end{array}$ & $-0,023$ & 0,077 \\
\hline
\end{tabular}

\begin{tabular}{|c|c|c|c|}
\hline Variabel & t hitung & Sig. & Ket \\
\hline (Constant) & 0,425 & 0,672 & \\
\hline $\begin{array}{l}\text { Kepercayaan } \\
\text { (X1) }\end{array}$ & 2,166 & 0,033 & Signifikan \\
\hline $\begin{array}{l}\text { Komitmen } \\
\text { (X2) }\end{array}$ & 2,740 & 0,007 & Signifikan \\
\hline $\begin{array}{l}\text { Komunikasi } \\
\text { (X3) }\end{array}$ & 2,584 & 0,011 & Signifikan \\
\hline $\begin{array}{l}\text { Penanganan } \\
\text { Masalah (X4) }\end{array}$ & $-0,301$ & 0,0764 & $\begin{array}{l}\text { Tidak } \\
\text { signifikan }\end{array}$ \\
\hline $\mathrm{R}=0,486$ & & \multicolumn{2}{|c|}{ Sig. $F=0,000$} \\
\hline R Square $=0,2$ & & \multirow{2}{*}{\multicolumn{2}{|c|}{$\begin{array}{l}\text { F hitung }=7,735 ; \alpha= \\
0,05 \\
\mathrm{k}=4 ; \mathrm{n}-\mathrm{k}-1=105-4- \\
1=100\end{array}$}} \\
\hline Adj R Square & 0,206 & & \\
\hline
\end{tabular}

Signifikan

$\overline{\text { Retensi Pelanggan }(\hat{\mathrm{Y}})=1,554+0,166 \mathrm{X} 1+}$ $0,268 \mathrm{X} 2+0,247 \mathrm{X} 3-0,023 \mathrm{X} 4+\mathrm{e}$.

Berdasarkan hasil analisis regresi berganda pada Tabel 1 ditemukan bahwa, lewat analisis ragam satu arah (ANOVA) mengindikasikan bahwa regresi secara statistik sangat signifikan dengan nilai $\mathrm{F}=$ 7,735 untuk derajat kebebasan $\mathrm{k}=4$ dan $\mathrm{n}$ $\mathrm{k}-1=105-4-1=100$, dan nilai $\mathrm{P}(P-$ value $)=0,000$, jauh lebih kecil dari $\alpha=$ 0,05 . 
Persamaan garis regresi linear berganda untuk metode kuadrat terkecil (least squares method) yang didapat ialah :

$\hat{\mathrm{Y}}=1,554+0,166 \mathrm{X} 1+0,268 \mathrm{X} 2+$ $0,247 \times 3-0,023 \times 4$

Penjelasan terhadap persamaan di atas sebagai berikut :

$\hat{Y}=$ Retensi Pelanggan, yang diduga; $\mathrm{X} 1=$ Kepercayaan; $\mathrm{X} 2=$ Komitmen; $\mathrm{X} 3=$ Komunikasi;dan $\mathrm{X} 4=$ Penanganan Masalah.

Nilai $\alpha$ konstanta sebesar 1,554 dimana nilai itu mempunyai arti bahwa jika variabel Kepercayaan (X1), variabel Komitmen (X2), variabel Komunikasi (X3), dan variabel penanganan masalah pelanggan tidak ada atau pada posisi 0 (nol), maka Retensi pelanggan (Y) dari PT. Erafone Manadosebesar 1.554.

Koefisien regresi b1 sebesar 0,166 menyatakan bahwa setiap penambahan atau peningkatan sebesar +1 dari Kepercayaan pelanggan, akan meningkatkan Retenssi pelanggan sebesar 0,166 atau 16,6\%.

Koefisien regresi b2 sebesar 0,268 menyatakan bahwa setiap penambahan +1 Komitmen pelanggan, akan meningkatkan retensi pelanggan sebesar 0,268 atau $26,8 \%$.

Koefisien regresi b3 sebesar 0,247, menyatakan bahwa setiap penambahan +1 komunikasi, akan meningkatkan retensi pelanggan sebesar 0,247 atau $24,7 \%$.
Koefisien regresi b4 sebesar $-0,023$, menyatakan bahwa setiap penurunan-1 penangan masalah, akan menurunkan retensi pelanggan sebesar 0,023 atau $-2,3$ $\%$.

Berdasarkan hasil analisis pada Tabel 1, diketahui bahwa nilai p-value untuk variabel kepercayaan, komitmen, dan komunikasi, ternyata lebih kecil dari 0,05 $(<0,05)$, sehingga ke tiga variabel bebas tersebut memiliki pengaruh secara individual atau parsial terhadap Retensi Pelanggan untuk setia berbelanja pada PT. Erafon Manado.

Adapun variabel kepercayaan memiliki nilai signifikansi sebesar 0,033 atau $<0,05$, variabel Komitmen memiliki signifikansi sebesar 0,007 atau <0,05, dan variabel Komunikasi memiliki signifikansi sebesar 0,011 atau < 0,05. Sementara itu variabel penanganan masalah memiliki signifikansi hanya sebesar 0,764 atau < 0,05 sehingga dinyatakan tidak signifikan.

Hal ini mengindikasikan bahwa secara individual atau parsial ke tiga variabel bebas (variabel kepercayaan, variabel komitmen dan variabel komunikasi), memiliki pengaruh yang signifikan terhadap retensi pelanggan konsumen produk-produk PT. Erafon Manado.

Berdasarkan hasil dari Tabel 1 ditemukan bahwa nilai signifikansidari 
Fhitung sebesar 0,000 $(<0,05)$, maka hipotesis (H5) yang menyatakan bahwa "Terdapat, kepercayaan, komitmen, komunikasi, dan penanganan secara simultan dan parsial berpengaruh signifikan terhadap customer retention pada PT. Erafone.

\section{Pembahasan}

\section{1) Pengaruh Kepercayaan Terhadap Customer Retention.}

Berdasarkan hasil analisis regresi berganda, dan uji-t, ditemukan bahwa variabel kepercayaan memiliki pengaruh signifikan dan positif terhadap retensi pelanggan untuk tetap berbelanja, khususnya pelanggan PT. Erafon Manado. Hubungan antara kepercayaan dan customer retention dalam penelitian ini menunjukkan hasil yang positif dan signifikan. Hasil penelitian ini sesuai dengan penelitian Christian (2004), dan Hidayat (2001) yang menemukan bahwa kepercayaan pelanggan berpengaruh terhadap customer retention tersebut dalam melakukan pembelian atau memanfaatkan suatu produk ataupun jasa.

\section{2) Pengaruh Komitmen Terhadap Retensi Pelanggan}

Berdasarkan hasil analisis regresi berganda, dan uji-t, ditemukan bahwa variabel Komitmen memiliki pengaruh signifikan dan positif terhadap customer retention untuk tetap berbelanja, khususnya pelanggan PT. Erafon Manado. Hubungan antara komitmen dan retensi pelanggan dalam penelitian ini menunjukkan hasil yang positif dan signifikan. Komitmen menjadi salah satu upaya yang berpengaruh untuk mempertahankan pelanggan dan menjaga hubungan jangka panjang antara kedua belah pihak, karena komitmen yang tinggi dari seorang pelanggan terhadap perusahaan akan di tunjukkan dengan keyakinan yang kuat dan penerimaan terhadap nilai-nilai yang diterapkan perusahaan. Komitmen sangat penting untuk menjamin keberlangsungan kerja sama dalam jangka panjang.

\section{3) Pengaruh Komunikasi Terhadap Retensi Pelanggan}

Mengacu pada hasil analisis regresi berganda, dan uji-t, ditemukan bahwa variabel Komunikasi memiliki pengaruh signifikan dan positif terhadap retensi pelanggan untuk tetap berbelanja, khususnya pelanggan PT. Erafon Manado. Hubungan antara komunikasi dan customer retention dalam penelitian ini menunjukkan hasil yang positif dan signifikan. Komunikasi sebagai pertukaran informasi antara pembeli dan penjual merupakan aspek yang sangat penting terhadap kesuksesan perusahaan. 
Komunikasi juga dapat menjadi media mengatasi masalah, melalui komunikasi perusahaan dapat menyelaraskan ekspektasi perusahaan dengan persepsi pelanggan. Dapat disimpulkan bahwa komunikasi pemasaran merupakan pola perusahaan yang ter-implikasi melalui aktivitas pemasaran seperti halnya merencanakan, menentukan harga, mempromosikan dan mendistribusikan barang dan jasa yang dapat memuaskan kebutuhan para pembeli yang ada maupun pembeli yang memiliki potensial. Aktivitas komunikasi bertujuan untuk menyebarkan informasi, menyampaikan pesan, mempengaruhi atau mem-bujuk, dan mengingatkan pasar pada produk yang di tawarkan perusahaan.

\section{4) Pengaruh Penanganan Keluhan Terhadap Customer Retention}

Mengacu pada hasil analisis regresi berganda, dan uji-t, ditemukan bahwa variabel Penanganan keluhan memiliki pengaruh negative dan tidak signifikan terhadap customer retention untuk berbelanja, khususnya pelanggan PT. Erafon Manado. Hubungan antara ke dua variabel dalam penelitian ini menunjukkan hasil yang negatif dan tidak signifikan.

Temuan penelitian ini mempertegas bahwa penanganan keluhan pelanggan oleh petugas yang kurang professional merupakan salah satu variabel yang tidak berpengaruh terhadap customer retention, khususnya customer retention untuk tetap berbelanja pada PT. Erafon Manado.

\section{5) Pengaruh Kepercayaan, Komit- men, Komunikasi dan Pena- nganan Keluhan Secara Bersama- Sama Terhadap Customer Retention.}

Berdasarkan hasil analisis regresi berganda, dan uji $\mathrm{F}$, ditemukan bahwa seluruh variabel independen yaitu Kepercayaan, Komitmen, Komunikasi, dan Penanganan Keluhan pelanggan secara bersama-sama atau simultan memiliki pengaruh langsung terhadap variabel dependen customer retention, khususnya pelanggan yang berbelanja pada PT. Erafone Manado. Hubungan antara keempat variabel tersebut secara bersamasama terhadap customer retention dalam penelitian ini menunjukkan hasil yang positif dan signifikan.

Keempat faktor tersebut dapat dibenarkan secara teori, karena retensi konsumen terhadap suatu produk, seperti produk elektronik sangat bergantung pada kepercayaan konsumen terhadap kualitas suatu produk elektronik. Dengan adanya kepercayaan terhadap kualitas produk, maka akan terjaga komitmen mereka, apalagi didukung dengan komunikasi dan 
penangan keluhan konsumen yang professional sehingga mereka tetap menjaga komitmen untuk tetap mengunakan produk tersebut.

\section{Kesimpulan}

Rata-rata ke tiga variabel bebas terkategori "sedang". Kepercayaan, komitmen, komunikasi berpengaruh secara individual dan parsial terhadap customer retention sedangkan variabel penanganan keluhan terkategori "tinggi" berpengaruh simultan terhadap customer retention. Sementara variabel tak bebas atau terikat terkategori "sedang".

Keempat variabel bebas berpengaruh secara signifikan dan simultan terhadap retensi pelanggan, sementara yang paling dominan pengaruhnya terhadap retensi pelanggan adalah kepercayaan pelanggan dalam menggunakan produk PT. Erafon Manado.

\section{Saran}

Mengingat kepercayaan terhadap kualitas produk, komitmen dan komunikasi belum optimal dicapai, maka diperlukan upaya-upaya konkrit dari pihak manajemen untuk meningkatkan ke tiga factor tersebut yang pada gilirannya diharapkan dapat meningkatkan customer retention terhadap produk PT. Erafon Manado.
Mengingat keempat variabel bebas berpengaruh positif dan signifikan terhadap customer retention, maka pihak manajemen perlu menjaga konsistensi persepsi pelanggan tersebut dan dapat mengalami perubahan yang lebih baik dan meningkat.

\section{Daftar Pustaka}

Danish, R. Q. dan Humayon, A. A. 2015. Factors Affecting Customer Retention in Telecom Sector of Pakistan. American Journal of Marketing Research. Vol. 1, No. 2 : 28-36.

Lapalelo, B. Pio, R. J. Tampi, J. R. E 2015. Pengaruh Sistem Informasi Pemasaran Dan Kualitas Pelayanan Terhadap Kepuasan Pelanggan Dan Loyalitas Pelanggan pada PT. Hasjrat Abadi Manado. Jurnal Administrasi Publik 1. Vol 1No 028, halaman 31-44.

Tauni, S dan Khan, R. I. 2014. Impact of Customer Relationship Management on Customer Retention in the Telecom Industry of Pakistan.Journal of Industrial Engineering. Vol.4, No.10

Priyatno, D, 2009. SPSS untuk Analisis Korelasi, Regresi, dan Multivariate, Yogyakarta: Gava Media.

Alghozali, H.I. 2011. Aplikasi Analisis Multivariate dengan Program IBM SPSS 19, Semarang: Badan penerbit Universitas Diponegoro.

Bataineh, A. Q. Ghaith, M. A. Hanadi, A. S dan Amer, M. S. 2015.The Effect of Relationship Marketing on Customer Retention in The 
Jorandian' Pharmaceutical Sector. International Journal of Business and Management. Vol $10: 117$ 131.

Martey, E. M. 2014. The Relationship Between Customer Retention And Customer Loyalty In The Restaurant Industry In Ghana. International Journal of Research. Vol 1, No 8, pp. 51-54 